\title{
Do translocal networks matter for agricultural innovation? A case study on advice sharing in small-scale farming communities in Northeast Thailand
}

\author{
Till Rockenbauch ${ }^{1}\left(\mathbb{D} \cdot\right.$ Patrick Sakdapolrak $^{2}$ (D) $\cdot$ Harald Sterly $^{2}$ (D)
}

Accepted: 27 March 2019 / Published online: 10 April 2019

(c) The Author(s) 2019, Corrected Publication August 2019

\begin{abstract}
Recent research on agricultural innovation has outlined social networks' role in diffusing agricultural knowledge; however, so far, it has broadly neglected the socio-spatial dimensions of innovation processes. Against this backdrop, we apply a spatially explicit translocal network perspective in order to investigate the role of migration-related translocal networks for adaptive change in a small-scale farming community in Northeast Thailand. By means of formal social network analysis we map the socio-spatial patterns of advice sharing regarding changes in sugarcane and rice farming over a period of five years. We find that, in translocally connected and mobile rural communities, a substantial share of advice originates from translocal levels. Translocal advice is dominantly provided through weak and formal ties with extension agencies and shared by few highly central larger-scale farmers within sparse local networks. This draws the picture of top-down translocal innovation flows driven by extension agencies and brokered through elite farmers. A closer look on institutional context and key actors of particular changes, however, suggests the potential of migration-related translocal networks and migration experience in fostering bottom-up innovations. Migration-related innovations transfers can promote adaptive capacity also among less favorably connected actors, especially if changes are geared towards limited household resources and are compatible with social practices of small-scale farming. We conclude that a translocal network perspective is instructive for research and extension interested in leveraging more inclusive agricultural innovation.
\end{abstract}

Keywords Agricultural innovation $\cdot$ Farmer advice sharing $\cdot$ Migration $\cdot$ Northeast Thailand $\cdot$ Social network analysis $(\mathrm{SNA}) \cdot$ Translocal knowledge transfers

The original version of this article was revised due to a retrospective Open Access order.

Electronic supplementary material The online version of this article (https://doi.org/10.1007/s10460-019-09935-0) contains supplementary material, which is available to authorized users.

Till Rockenbauch

till.rockenbauch@uni-bonn.de

Patrick Sakdapolrak

patrick.sakdapolrak@univie.ac.at

Harald Sterly

harald.sterly@univie.ac.at

1 Department of Geography, University of Bonn, Meckenheimer Allee 166, 53111 Bonn, North Rhine-Westphalia, Germany

2 Department of Geography and Regional Research, University of Vienna, Universitätsstraße 7/5, 1010 Vienna, Austria

\section{Abbreviations}

BAAC Bank of agriculture and agricultural cooperatives DOAE Department of agricultural extension SNA Social network analysis

\section{Introduction}

Agricultural innovation is essential for maintaining productive agricultural systems (Wossen et al. 2013; Mekonnen et al. 2018) and a major contribution to rural development (Conley and Udry 2001; Bandiera and Rasul 2006). In light of increasing climate-related risks, agricultural innovation is also gaining attention as an important contribution to climate change adaptation and food security (Mikhail et al. 2010; Rodima-Taylor et al. 2012). But as innovation processes are often poorly understood (Bandiera and Rasul 2006), facilitating adaptive change remains a key challenge. 
In recent years, research has taken major steps towards understanding agricultural innovation processes, highlighting the role of social networks in the diffusion of knowledge for adoption and implementation of improved agricultural crops and practices (Conley and Udry 2001; Bandiera and Rasul 2006; Spielman et al. 2011; Isaac 2012; Wossen et al. 2013; Thuo et al. 2014; Salpeteur et al. 2017). However, in doing so, most studies have conceptualized social relations as being self-contained (Matous 2015) and have largely neglected the spatiality of social networks (Rockenbauch and Sakdapolrak 2017).

Omitting the spatial character of social networks (Das 2001; Jessop et al. 2008) risks oversimplifying agricultural innovation, especially when studying agricultural transformations in the Global South. In countries such as Thailand, where migration is a major strategy for sustaining rural livelihoods (Promburom and Sakdapolrak 2012; Rigg et al. 2012), translocal networks are increasingly facilitating the flow of information, ideas and knowledge between different rural areas and between rural and urban areas. These translocal networks, it has been argued, hold the potential to strengthen adaptive capacity in rural communities (Scheffran et al. 2012; Sakdapolrak et al. 2016). However, the question remains to what extent and under which conditions translocal networks facilitate adaptive agricultural changes.

Our study aims at closing this gap by applying a translocal network perspective on agricultural innovations in a smallscale farming community in Northeast Thailand. Drawing on a combination of formal social network analysis (SNA), a questionnaire survey, and semi-structured interviews, we are addressing the following questions:

1. To what extent are translocal networks relevant for facilitating agricultural change?

2. How is knowledge relevant for agricultural changes transferred through translocal networks?

3. What are conditions of, and who are key actors in translocal knowledge transfers?

By answering these questions we provide detailed insights into the socio-spatial structure underlying agricultural changes in Northeast Thailand. This way, our paper overcomes the local bias of previous network assessments and contributes to the discussion on the role of translocal networks in agricultural innovation.

\section{Theoretical background and conceptual framework}

Agricultural innovation comprises both technological and non-technological changes in the agricultural sector (Schut et al. 2015), which result from interactive learning between heterogeneous sets of actors (Klerkx et al. 2010). The knowledge required for introducing and maintaining these changes can be acquired through "learning by doing" (a function of one's own innovative capacities) or through learning "from others" (a function of one's social network) (Spielman et al. 2011). Although the understanding of social networks' role in agricultural innovation has steadily advanced, it still lacks the consideration of agricultural innovation's spatial dimension, and in particular of mobility and migration (Rockenbauch and Sakdapolrak 2017).

\section{Agricultural innovation from a social network perspective}

A network perspective overcomes linear models of innovation diffusion and conceives of agricultural innovation as a process of exchanging knowledge through networks of communication and observation within agricultural innovation systems (Conley and Udry 2001; Klerkx et al. 2010; Spielman et al. 2011; Isaac 2012). These innovation networks are comprised of dyadic interactions between users and producers of knowledge and involve knowledge flows between heterogeneous actors involved in innovation systems (Arora 2012), such as representatives of public institutions, NGOs and the private sector (Klerkx et al. 2010; Spielman et al. 2011). To explain knowledge diffusion within innovation networks, social network scholars have focused on different network features: (i) tie characteristics, (ii) actor network position, (iii) network structure, or a combination of these network features.

For tie characteristics, it has been argued that non-redundant weak ties bridge actors of distant subgroups and are important for acquiring new knowledge (Granovetter 1973). Contrastingly, strong ties that bond closely related actors of the same subgroup involve high levels of trust and reciprocity and hence are expected to have positive effects on the diffusion of existing knowledge. A lack of either strong bonding or weak bridging ties, accordingly, might hamper innovation (Newman and Dale 2005; Bodin and Crona 2009). More specifically, authors have highlighted the role of linking ties between local actors and institutional representatives, such as extension staff or researchers, as a means of closing the gap between informal farmer networks and formal knowledge systems (Isaac 2012; Matous et al. 2013).

For actor network position, researchers have argued that actors centrally placed in knowledge-exchange networks tend to be more knowledgeable (Calvet-Mir et al. 2012) and more influential (Bodin and Crona 2009). Such actors are thus more likely to be agents of change (Isaac et al. 2014), acting either as facilitators or as bottlenecks of innovation flows (Bourne et al. 2017). Particular importance has been attributed to information brokers, strategically positioned actors transferring information between actors of different 
subgroups, for example between extension staff and local farmers (Bodin et al. 2006; Isaac 2012). By connecting and mediating between otherwise unconnected networks, these "boundary spanning" individuals can tap diverse sources and types of knowledge and hence facilitate agricultural innovation (Klerkx et al. 2010).

For network structure, it has been argued that agricultural innovation requires the right mix of different structural network properties (Newman and Dale 2005). For example, centralized networks-networks with only a few highly connected actors-have been shown to foster innovation diffusion, as information can effectively be distributed among network members (Bodin and Crona 2009). At the same time, high centralization might result in reduced access to diverse information sources, and thus prevent social learning (Bodin et al. 2006). Similarly, dense and redundant networks might foster the spread of information through increased accessibility to information but at the same time can lead to a homogenization of knowledge within closed subgroups (Bodin et al. 2006). In contrast, networks of low density might invite new knowledge, whereas the exchange of existing knowledge might be impeded (Isaac 2012). Against this background, it has been argued that agricultural innovation necessitates sparse but efficient networks (Isaac 2012) of low redundancy, high actor diversity (Isaac and Matous 2017), and few strategic bridging actors that are able to tap into diverse sources of knowledge (Isaac et al. 2014).

\section{Incorporating geographical space and mobility: towards a translocal network perspective}

While a social network perspective draws attention to the social fabric underlying innovation processes, relatively little is known about how innovation processes work at and between spatial scales (Binz et al. 2014). Only a few studies have addressed the role of spatiality in agricultural innovation networks: Whilst, in general, geographical distance presents an obstacle to social learning and behavioral diffusion (Matous et al. 2013), Wossen et al. (2013) find that spatial distance between network actors is positively related to the adoption of sustainable land use practices, as farmers are more likely to learn something "new" from distant peers; and Matous and Todo (2018) reveal that farmers with geographically long ties are more likely to adapt to environmental change. One central assumption underlying this argument is that spatial extensive networks connect farmers with diverse environmental experiences and environmental memory (Isaac et al. 2014; Matous and Todo 2018). In this case, long-distance ties can significantly reduce topological distance in a social network and facilitate rapid knowledge diffusion, especially if combined with strong local networks (Isaac and Matous 2017).
Obviously, long-distance ties matter more in remote rural communities constrained by information and resource scarcity than in areas with abundant communication and transport (Matous and Todo 2018). Given advancing mobility (Ellis 2003) and progressing agrarian transformation (Rigg 2006) in many countries of the Global South, however, remote communities are the exception rather than the norm. Marketization and de-localization of rural livelihoods foster the decline of customary informal networks and increase the dependency on external and formalized relations (Berdegué et al. 2014; Rigg and Oven 2015). At the same time, rural livelihoods are becoming more diverse and multi-sited (Rigg and Oven 2015). The increasing frequency and diversity of interactions blur sharp economic, social, and cultural differences between "the rural" and "the urban", blending into a continuous gradient of networked translocal spaces (Berdegué et al. 2014; Steinbrink 2009).

One important aspect of the de-localization of rural livelihoods is migration-a major livelihood strategy in many rural areas (Ellis 2003; Rigg 2006). As social ties between migrants and the sending households are usually not cut but stretched between places, migration fosters the emergence of translocal networks between areas of origin and destination (Brickell and Datta 2011; Greiner and Sakdapolrak 2013). As these translocal networks facilitate the exchange of ideas, knowledge, and resources between the origin and destination of migrants they may strengthen adaptive capacity in rural communities (Scheffran et al. 2012; Sakdapolrak et al. 2016).

So far, few studies have investigated the effect of migration and translocal networks on agricultural innovation. For example, Scheffran et al. (2012) conclude from three case studies in Western Africa that translocal migrant networks channel information about new crops and improved practices and should thus be recognized as a means of climate change adaptation. In a study on agricultural communication networks between migrant and non-migrant farmers in Northern Ghana, Isaac et al. (2014) show that migrant farmers are positioned more centrally in agricultural communication networks, tend to more successfully apply sustainable management practices and are brokers between otherwise unconnected, socially and geographically distant subgroups. Another study on knowledge sharing between semi-nomadic pastoralists in India concludes that farmers' agricultural knowledge status is more associated with membership in migration networks than with membership in acquaintance networks (Salpeteur et al. 2016). Whilst these studies make the point for considering translocal networks and migration, they lack a spatially explicit approach that accounts for the social and spatial structure of agricultural innovation networks (Rockenbauch and Sakdapolrak 2017). 


\section{Research framework}

This study, thus, adopts a translocal network perspective on agricultural innovation in a small-scale farming community in Northeast Thailand.

We conceptualize local farmers' capacity to innovate, and thereby adapt their agricultural livelihoods, as critically depending on networks of communication between various actors. Accounting for the de-localization of rural livelihoods (Rigg 2006) and drawing on developments in migration research (Brickell and Datta 2011; Greiner and Sakdapolrak 2013), we conceive of agricultural innovation networks as socio-spatial in nature (Das 2001; Jessop et al. 2008) and hence conceptualize them in a spatially explicit manner.

Translocal innovation networks are composed of local and translocal actors and, respectively, local and translocal ties. Translocal ties entail either formal ties to institutional representatives or informal ties to individual actors. Formal ties tend to be translocal due to often centralized institutional landscapes (e.g. extension offices at district level). Instead, informal translocal ties are often related to migration of family or household members. These migration-related translocal ties connect distant but closely related actors that are embedded in different socio-economic and agro-ecological contexts and therefore can provide access to new knowledge and facilitate agricultural innovation (Scheffran et al. 2012; Wossen et al. 2013; Sakdapolrak et al. 2016; Matous and Todo 2018). Besides direct knowledge exchanges, agricultural innovation might also be facilitated by indirect translocal knowledge exchanges, such as through experience returning migrants bring back to places of origin (Isaac et al. 2014; Salpeteur et al. 2016).

Figure 1 presents our conceptual framework. We conceptualized translocal agricultural innovation networks as advice sharing networks between actors involved in the agricultural sector, including farmers and non-farmers, public institutions, and private sector representatives at various spatial levels. In these networks, ingoing ties indicate advice seeking and outgoing ties indicate provision of advice. Translocal knowledge transfer through these networks can be assessed by looking at tie characteristics, actor network position, and overall network structure.

Tie characteristics we define by the type of advice exchanged: a) the exchange of ideas and recommendations (adoption advice), and $\mathrm{b}$ ) the exchange of instrumental advice and problem solving (implementation advice). Further we consider: tie locality (local ties originating from the same village or sub-district level/translocal ties originating from district to international levels); tie strength (strong ties/weak ties, according to closeness and frequency of contact); and tie formalization (informal ties connecting to migrating household members, relatives, neighbors or

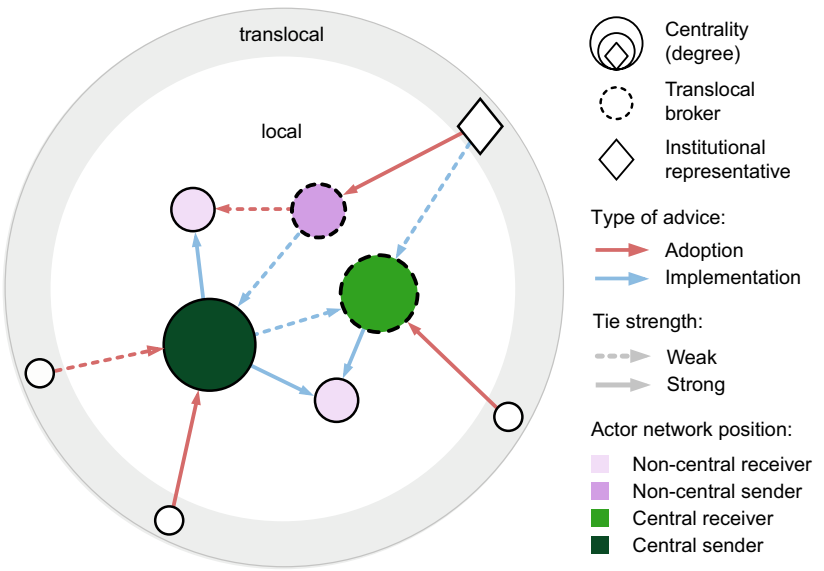

Fig. 1 Conceptual translocal advice sharing network

friends/formal ties connecting to institutional representatives, such as extension staff or service providers).

Actor network position we distinguish by two network features: actors' degree centrality (the number of ties an actor possesses), and their role in sharing advice (providing or receiving advice). Accordingly, actors can be classified as central sender (well-connected, mostly providing advice), central receiver (well-connected, mostly receiving advice), non-central sender (less-connected, mostly providing advice) and non-central receiver (less-connected, mostly receiving advice). According to involvement in translocal advice sharing, we further define translocal brokers as actors transmitting a particular type of advice between translocal and local actors.

Network structure we assess by two measures: network centralization - the degree to which centralities differ between network actors, and network density - the number of existing ties divided by the number of possible ties between actors (Bodin and Crona 2009).

\section{Methods and procedures}

\section{Site description}

This study was conducted within a research project focusing on climate change and migration in Thailand. Data collection took place from June to August 2016 in Ban Chai sub-district, Udon Thani province (Fig. 2). As in other areas of Northeast Thailand, rural livelihoods in Ban Chai are in transition from small-scale rice farming to the more diversified, market-oriented production of cash crops (Rambo 2017; Choenkwan and Fisher 2018). Driven by market developments and policies, the sub-district of Ban Chai has experienced a sharp increase in sugarcane plantations at the expense of rice farming, grazing and forest land. At the same 
Fig. 2 Location of the study site. Layout by the authors Source Global Administrative Areas, www.gadm.org

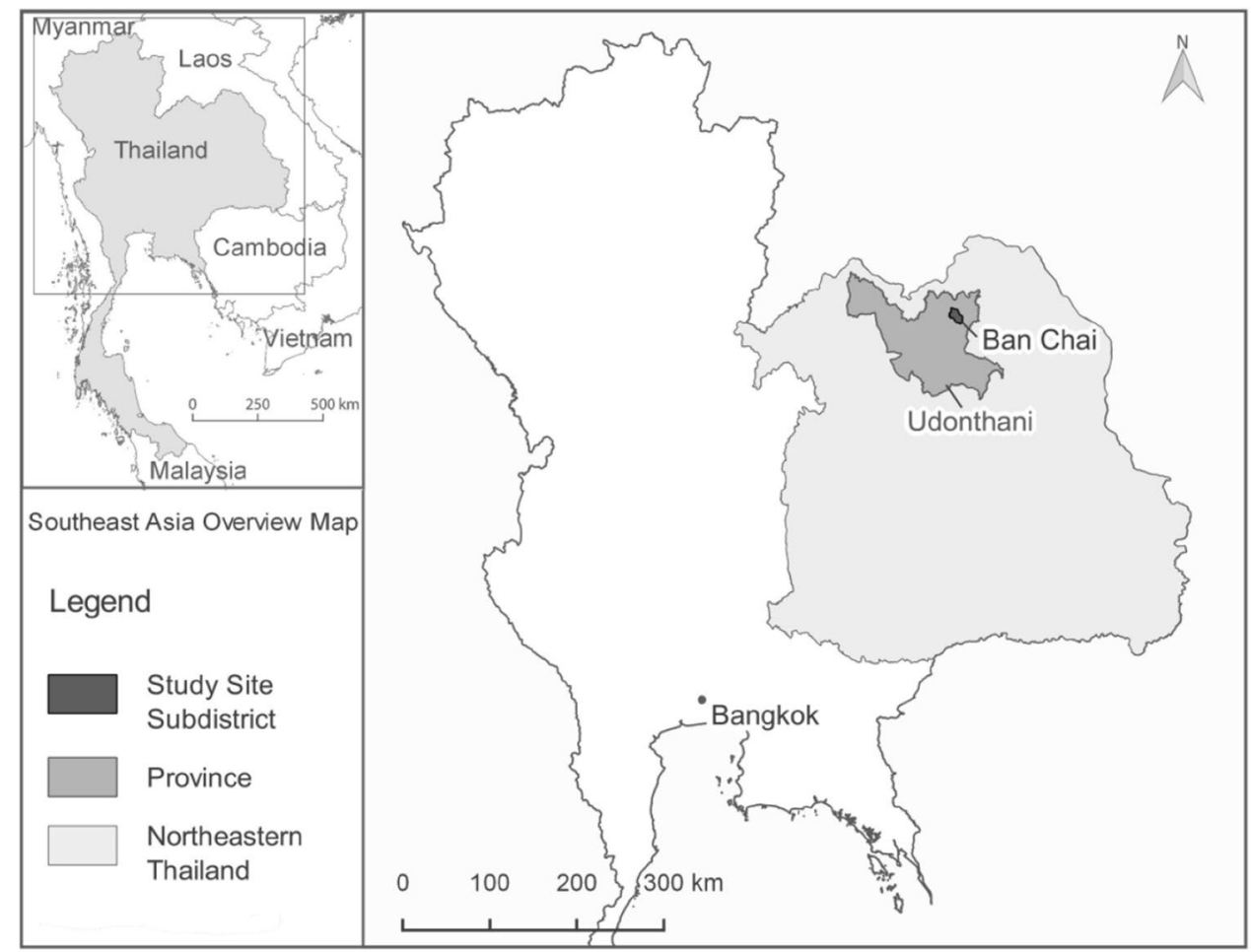

time, increasing variability in rainfall patterns in Northeast Thailand is placing stress on agricultural productivity, thereby increasing the need to adapt and explore alternative agricultural crops and practices (Mikhail et al. 2010; Naruchaikusol 2016; Choenkwan and Fisher 2018). Typical of Northeast Thailand, internal and international labor migration is a major livelihood strategy in Ban Chai, resulting in increasing translocal connectedness and multi-sited household footprints (Rigg and Salamanca 2011; Peth et al. 2018; Porst and Sakdapolrak 2018). With its exposure to climate change, its high rate of migration and the rapid change of its agricultural systems, the sub-district of Ban Chai provides a good example for studying the role of translocal networks in agricultural innovation.

\section{Data sampling and processing}

For assessing translocal advice sharing-networks, we applied methods of formal SNA (Wasserman and Faust 1994). SNA is most powerful for assessing and analyzing socio-centric networks defined as a finite set of actors and the social relations between them (Hennig et al. 2012). However, boundaries of farmer networks are difficult to define (Bourne et al. 2017), in particular in a translocal context. Broader definitions of the unit of analysis (e.g. migration system) would render assessing all actors and ties impossible, whereas narrower ones (e.g. village) would omit ties spanning different places. Alternatively, assessing ego-centric networks provides insights into the social embeddedness of a particular actor (ego) without limiting the number and geographical location of network actors (alters) beforehand. However, ego-centric networks provide limited information on network structure (Hennig et al. 2012).

Against this background, our research design combines ego-centric and socio-centric approaches. To assess egonetworks, we applied the name generator technique (Marsden 2005). This technique allows network alters and their attributes to be identified based on a set of predefined questions. For sampling egos, we applied a snowball technique, systematically following alters of already interviewed egos. Merging all sampled ego-networks, we constructed a partial socio-centric network that can be analyzed for tie characteristics and network structure, provided care is taken regarding the interpretation of results (Scott 2013; Ricciardi 2015).

Interviews were based on a standardized questionnaire consisting of two parts (see Online resource 1). Part A focused on agricultural livelihoods and migration, comprising inter alia agricultural changes, households' migration involvement and attitude towards migration, land use and ownership, and sources of income and information. Part B focused on advice sharing networks. To prevent the problem of fixed choices (Kossinets 2006), we limited network assessment to specific agricultural changes, instead of limiting the number of possible respondents. Therefore, farmers were asked to identify the most relevant changes in crops, practices and businesses over the last five years (2011-2016) and to name alters who provided advice in terms of ideas and recommendations and advice in terms of implementation 
and continuation of changes. Additionally, we asked for alters with whom farmers exchanged general agricultural information. For each of these alters, we asked the interviewee to identify the frequency of contact, perceived closeness and current location.

We started snowball sampling with two randomly selected farmers in a randomly selected village within the sub-district. Follow-up interviews were conducted with all alters located in the starting village, and with those alters within the sub-district that were identified by interviewees located in the starting village. This procedure was continued until $20 \%$ of all households in the starting village had been interviewed. After reaching this threshold, only alters identified during preceding interviews were interviewed, without following-up on any new alters. A total of 61 farmer interviews were conducted, of which 60 were selected for network analysis. Additionally, we conducted semi-structured interviews with key actors (either in terms of local or translocal connectedness) to gain a deeper understanding of their role in the innovation network. To understand the institutional context of agricultural changes, we also conducted semi-structured interviews with institutional representatives such as the village deputy chief or with district extension staff.

Statistical analysis of agricultural changes, network patterns and actor characteristics was conducted using STATA; while network visualization was performed in Gephi. For the purpose of network analysis, we constructed a partial innovation network, including all actors providing or receiving advice on agricultural changes between the year 2011 and 2016, whereby members of the same household were treated as one single actor, except for migrating household members. From this network we derived weighted innovation networks for selected agricultural changes (e.g. changes regarding rice farming) in which tie weight indicates the number of different types of support provided (adoption, implementation, general).

For each network, we calculated tie characteristics including the number and share of ties according to locality (local/ translocal), tie strength (weak/strong) and type of advice (adoption/implementation/general). To indicate tie strength, we referred to the median of the product of closeness and the frequency of contact (expressed by interviewees on a fourlevel Likert item). Local ties we defined as ties connecting actors at the village and sub-district level and translocal ties as ties spanning beyond.

For classifying actor network positions, we referred to degree centrality and advice sharing behavior of interviewed farmers (egos). Central actors we defined as actors with a higher degree centrality than the average degree centrality in the respective network. Senders of advice we defined as actors with a ratio of out- and in-degree equal to or higher than one, and receivers as actors with a ratio of out- and in-degree lower than one. Additionally, we defined translocal brokers as actors receiving a particular type of advice on a specific change (e.g. adoption advice on rice) from translocal actors and providing the same type of advice on the same change to local actors.

While the calculation of tie characteristics and network position incorporated all ties and actors, the calculation of structural features was conducted for local networks of interviewed farmers (egos) only (excluding translocal actors and ties). For calculating centralization, we subtracted the centrality score of each network actor from the maximum centrality score in the network and summed up differences. This sum was then divided by the maximum possible sum of differences. For calculating network density we divided the observed number of ties by the maximum possible number of ties (Wasserman and Faust 1994). Both network centralization and density were calculated for directed and dichotomized networks.

\section{Methodological considerations}

Whilst the applied research design has proven successful in revealing the socio-spatial patterns of agricultural advice sharing that would have been omitted by community-centric approaches, it comes with some methodological limitations.

First, this study defines network ties not as general exchange and communication about agricultural issues (e.g. Isaac et al. 2014) but as advice sharing regarding already materialized agricultural changes. Our study implies that networks do not reflect the general social structure through which innovations are potentially diffused, but the cumulative structure of past diffusions' pathways. On the one hand, this network definition restricts the scope for analytical approaches, but on the other hand, a change-based network definition provides room for descriptive interpretation, as each tie can be related to particular changes.

The second limitation lies in the applied sampling design. In general, snowball sampling tends to focus on closely related subgroups and hence tends to omit structural holes between weakly connected network members (Scott 2013). Moreover, the snowball-sampled networks are incomplete, as we followed-up only local alters and did not follow-up alters of interviewees located outside the starting village. We have accounted for this bias by building our analysis on node-specific network measures of interviewed farmers (e.g. degree centrality and ratio of in- and out-degree), and by calculating structural network measures only for local networks of interviewed farmers (egos).

Third, the applied approach omits temporal dynamics (Violon et al. 2016) and indirect forms of knowledge transfers (e.g. observation, embodied experiences), which may occur between gaining new knowledge and applying this knowledge (Bandiera and Rasul 2006). In order 
to contextualize network structure, and, more specifically, to disentangle direct and indirect knowledge transfers, we applied a mix of quantitative and qualitative network approaches (Hollstein and Straus 2006; Bolíbar 2015). This entails the combination of network data with data on institutional context and key actors derived from questionnaire survey and semi-structured interviews.

\section{Results}

\section{Current agricultural changes in the study site}

Data from farmer questionnaires indicate rapid changes in farming systems in the study site, from mainly subsistencebased rice farming to commercial cash-crop production. Figure 3 shows that, between the years 2011 and 2016, sugarcane has rapidly gained popularity in terms of the number of applied changes. In 2016, almost $80 \%$ of all interviewed farmers grew sugarcane, with almost $60 \%$ having started sugarcane farming since 2011. Sugarcane cultivation is unevenly distributed among farmers. Less than $20 \%$ of all interviewed farmers cultivated more than 50 rai ( 8 hectares) of sugarcane - the minimum land size required for paying-off the credit for a big tractor-while land cultivated by largerscale farmers accounted for $70 \%$ of all reported sugarcane land.

At the same time, Fig. 3 suggests profound changes in rice farming. As a means of saving labor and investment costs, more than $85 \%$ of all interviewed farmers have, between the years 2011 and 2016, introduced rice broadcasting-either by hand or machine-as an alternative to transplanting. To reduce weeds, broadcasting is often combined with rice cutting, a technique originally developed in central Thailand and introduced to the study site only recently. Another recent

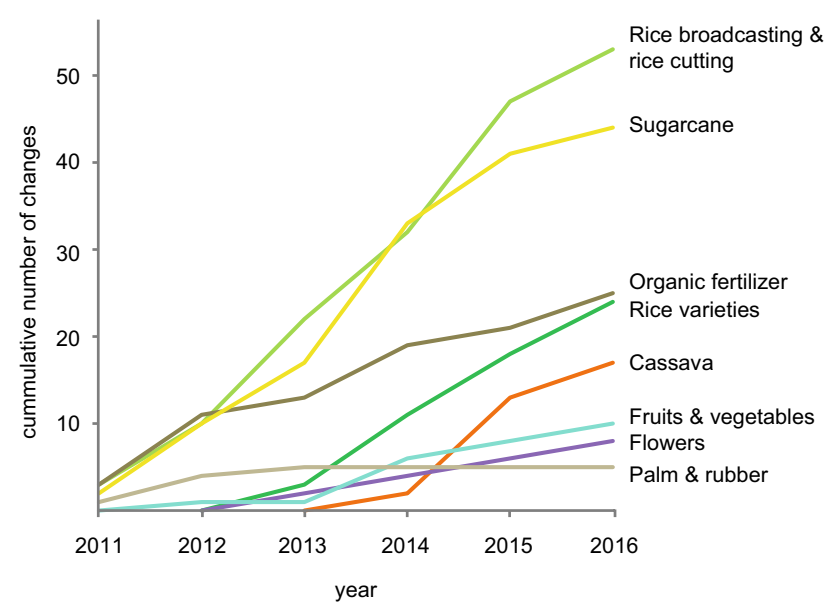

Fig. 3 Cumulative number of agricultural changes between 2011 and 2016 , as reported by interviewed farmers $(n=60)$ change in rice farming is the diversification towards high price specialty varieties for urban markets.

Furthermore, interviews indicate changes such as the application of organic fertilizer or the cultivation of cassava, palm, rubber, fruits, vegetables, and flowers. The spread of these changes, however, has remained limited due to high investment costs, lack of labor, or volatile market prices. Hence, in the following, we focus only on advice sharing regarding sugarcane and rice farming, which are also the most important crops in terms of household income and food security.

\section{Distribution and composition of advice}

This section provides an overview of the distribution and composition of advice regarding changes in sugarcane and rice farming between the years 2011 and 2016. This way we provide an indication of the extent to which agricultural changes are facilitated by translocal advice.

According to Fig. 4, advice on changes in sugarcane and rice farming was dominantly exchanged between closely and frequently related actors at the local level. Advice regarding changes in rice farming was mostly provided through strong ties $(60 \%)$, while advice regarding changes in sugarcane farming was almost equally provided through strong (51\%) and weak ties (49\%). Ties between local actors provided the majority of advice regarding changes in rice (72\%) and sugarcane farming (76\%), whereas the dominance of strong local ties was more pronounced with regard to rice farming (53\%) than with regard to sugarcane farming (42\%). Advice by translocal actors located outside the sub-district was more frequent for changes in rice farming (28\%) than for changes in sugarcane farming (24\%). Translocal ties were mostly weak and were more frequently providing ricerelated advice (21\%) than sugarcane-related advice (14\%). Translocal advice by closely related translocal actors was slightly more frequent for changes in sugarcane farming $(10 \%)$ than for changes in rice farming $(7 \%)$.

Figure 4 further reveals that advice regarding changes in sugarcane farming was mostly providing incentives for adoption, whereas advice regarding changes in rice farming was equally concerned with adoption and implementation. Adoption advice regarding changes in sugarcane and rice farming was mostly provided through strong or local ties, in particular through strong local ties. Differences exist with regard to implementation advice, however. While implementation advice regarding changes in sugarcane farming was equally provided through strong and weak ties, implementation advice regarding rice farming was mostly provided through strong ties. At the same time, implementation advice regarding changes in rice farming was to a relatively higher extent provided through translocal ties, and in particular through weak translocal ties. 

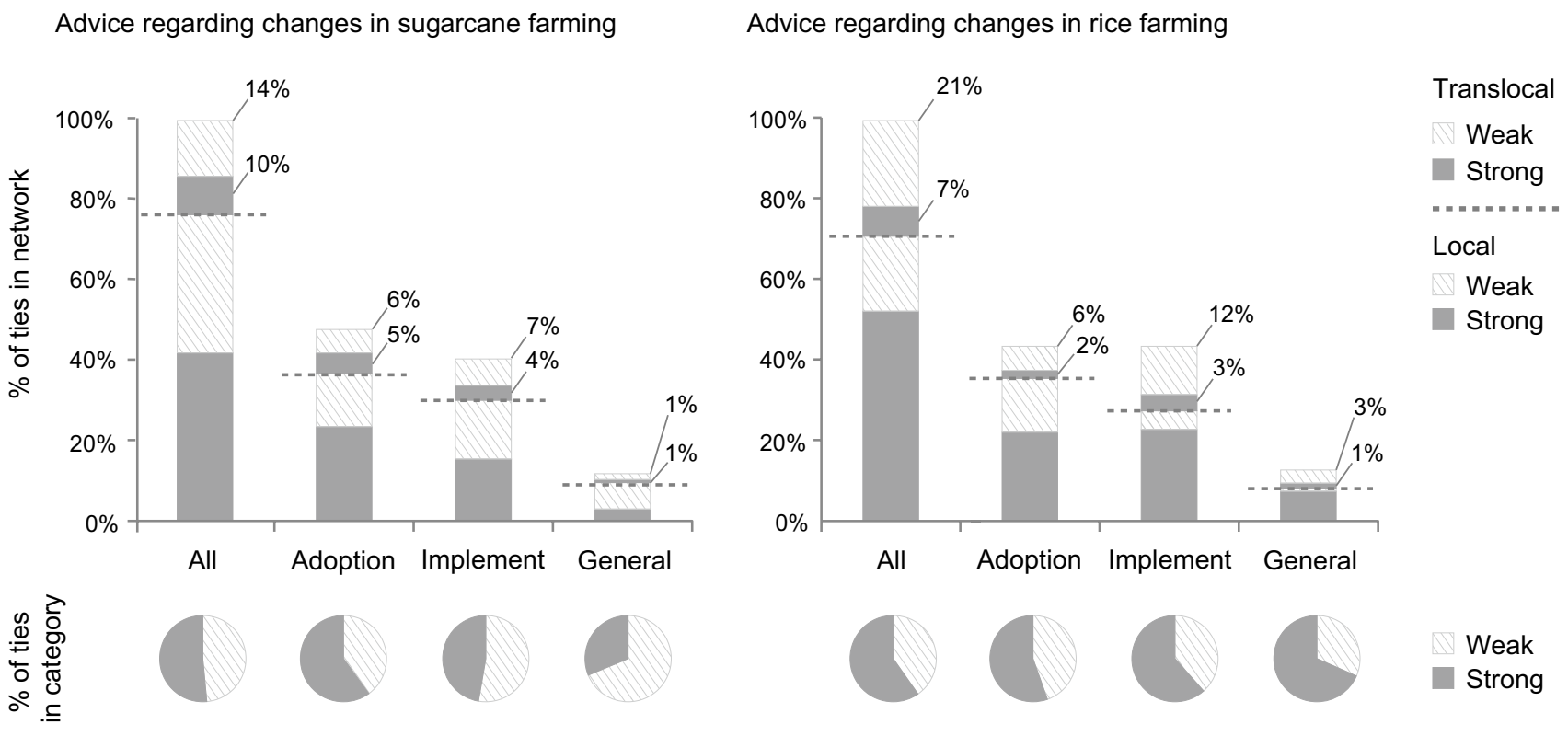

Fig. 4 Distribution and composition of advice regarding changes in sugarcane and rice farming, in percentage of ties by type of advice, tie locality, and tie strength

Figure 5 provides deeper insights into the composition of translocal advice. For changes in both sugarcane farming and rice farming, translocal advice was mostly provided through formal ties. While formal extension-related advice was mostly provided through weak translocal ties, informal migration-related advice was to an equal extent provided through weak and strong translocal ties. With regard to the type of advice, translocal advice regarding changes in sugarcane farming facilitated adoption and implementation to an equal extent; while translocal advice regarding changes in rice farming was mostly concerned with implementation. For both changes in sugarcane farming and changes in rice farming, translocal adoption advice was to an equal extent provided through formal extension-related advice and
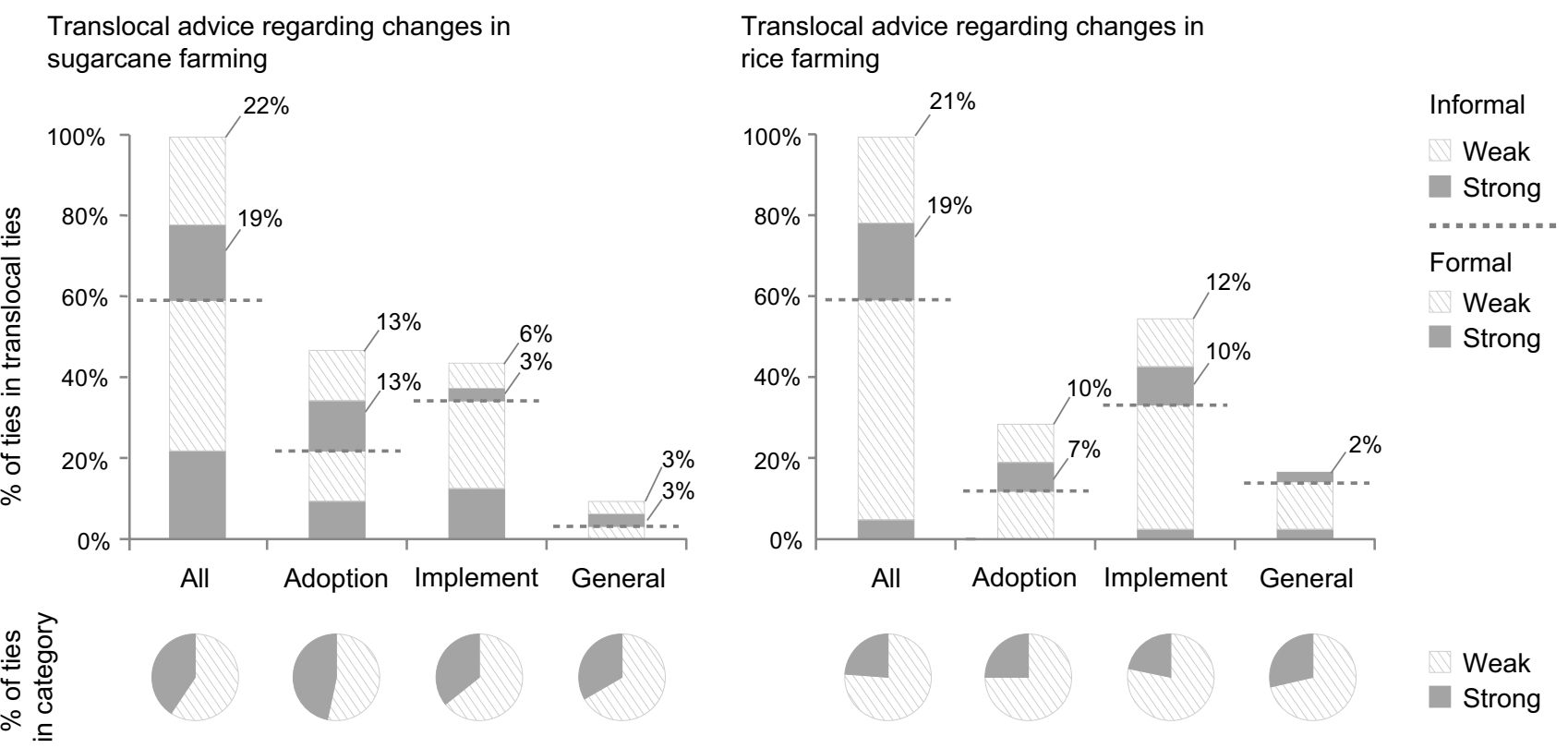

Fig. 5 Distribution and composition of translocal advice regarding changes in sugarcane and rice farming, in percentage of translocal ties by type of advice, tie formalization, and tie strength 
informal migration-related ties, whereas translocal implementation advice was mostly provided through formal extension-related ties.

\section{Advice sharing networks}

In this section we characterize the social and spatial patterns of advice sharing networks regarding changes in sugarcane and rice farming derived from a total of 60 farmer ego-networks. In doing so, we provide more detailed insights in how advice on agricultural changes is transferred between local and translocal actors.

Figure 6 presents the sociograms of the sugarcane network and the rice network, while Tables 1 and 2 provide an overview of selected network characteristics (sociograms and tables disaggregated by types of support see Online

Sugarcane network:

Ties: $n T=136$ (incl. 32 transl. ties)

Actors: $n A=69$ (incl. 44 egos \& 19 transl. actors)

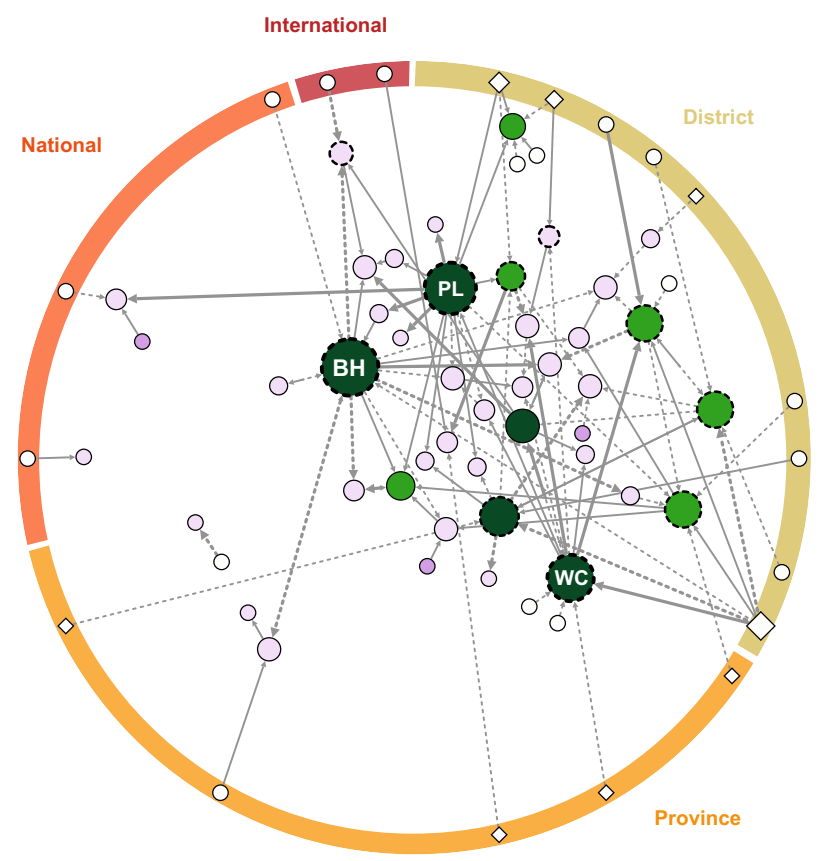

Tie weight:

number of different types of advice provided (adoption

Tie strength:
$-\rightarrow$ Weak
$\rightarrow$ Strong

Node size implementation, general) resource 2). The sugarcane network (69 actors, 136 ties) is smaller than the rice network (93 actors, 149 ties). Both networks show similar shares of translocal actors (actors at the outer circle), with institutional representatives (diamond-shaped nodes) being more frequent and more equally spread across geographical levels in the rice network than in the sugarcane network. In the sugarcane network, institutional representatives, in particular at district level, provide the majority of translocal advice, which is received by few highly central local actors. In contrast, in the rice network, translocal advice originates more equally from translocal actors at different geographical levels and is more equally received by local actors of different centrality.

Table 2 provides an overview of selected characteristics of local advice sharing networks between interviewed farmers (egos). Low levels of density indicate that communication
Rice network:

Ties: $n T=149$ (incl. transl. ties 42) Actors: $n A=93$ (incl. 56 egos \& 27 transl. actors)

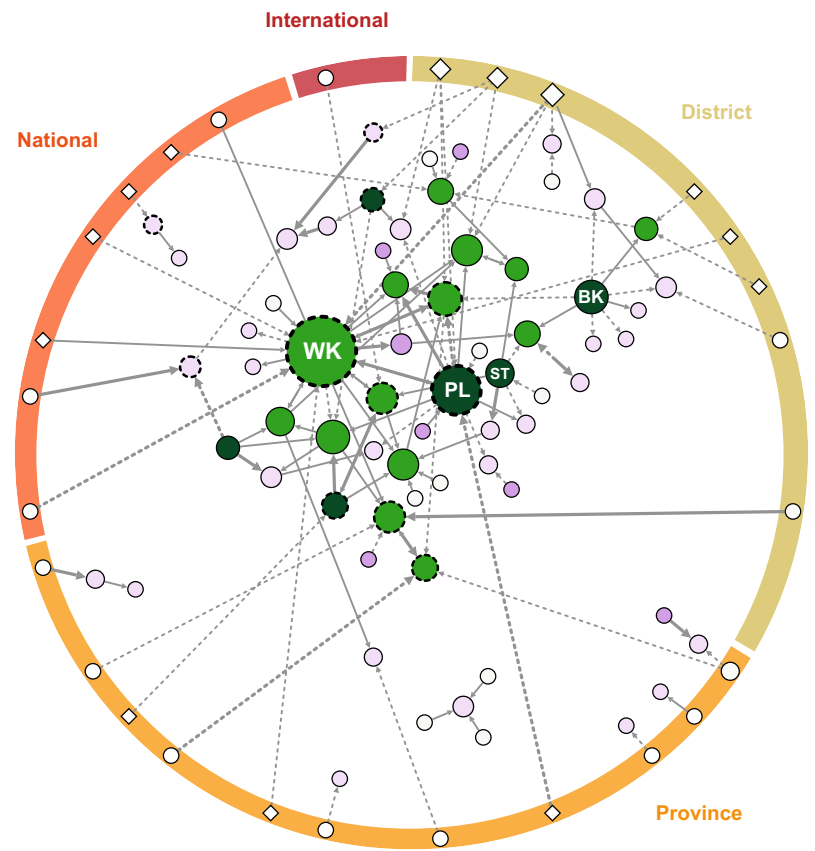

Actor network position:

Non-central receiver - Non-central sender

- Central receiver

Central sender
Fig. 6 Sociograms of the sugarcane network and the rice network: Actors inside the circles represent local farmers (village and subdistrict); actors on the outer circles represent translocal actors (district-international); diamonds indicate institutional actors; tie style indicates weak ties (dotted) and strong ties (continuous); tie width represents the number of different types of advice provided (adoption, implementation, general); node size represents weighted ego- network size, and node color indicates actor network position (noncentral receiver/sender, central receiver/sender); dotted nodes indicate translocal brokers; acronyms identify key actors; white nodes indicate actors, who declined interviews or were not captured by the sampling design. Networks are subsets of the overall partial network. This explains why local networks include subgroups and isolates, despite the fact that we used a snowball-sampling strategy 
Table 1 Selected characteristics of the sugarcane network and the rice network

\begin{tabular}{lll}
\hline Network characteristics & Sugarcane network & Rice network \\
\hline Actors (abs.) & 69 & 93 \\
Ties (abs.) & 136 & 149 \\
Translocal actors (abs./\% all) & $19 / 28 \%$ & $27 / 29 \%$ \\
Institutional representatives (abs./\% of transl. actors) & $9 / 47 \%$ & $15 / 56 \%$ \\
Translocal ties (abs./\% of all) & $32 / 24 \%$ & $42 / 28 \%$ \\
Formal translocal ties (abs./\% of transl. ties) & $19 / 59 \%$ & $25 / 60 \%$ \\
\hline
\end{tabular}

Networks are weighted, with tie strength indicating the number of different types of support provided (adoption, implementation, general)

Each tie is indicating the provision of one type of support (either adoption, implementation, or general)

\begin{tabular}{lll}
\hline Network characteristics & Local sugarcane network & Local rice network \\
\hline Egos (abs.) & 44 & 56 \\
Local ties between egos (abs.) & 78 & 80 \\
Translocal connected egos (abs./\% of egos) & $16 / 36 \%$ & $24 / 43 \%$ \\
Translocal broker (abs./\% of egos) & $10 / 23 \%$ & $11 / 20 \%$ \\
Density (directed) & 0.041 & 0.026 \\
InCentralization & 0.079 & 0.067 \\
OutCentralization & 0.274 & 0.180 \\
\hline
\end{tabular}

Local networks are comprised of interviewed farmers (egos) and local ties between them

Density and centralization are calculated for dichotomized local networks between local farmers operate through sparse, non-redundant networks. Of particular low density is the local rice network, which is characterized by a higher share of unconnected subgroups. Both networks are characterized by low indegree-centralization, implying that local farmers equally receive advice from each other. With regard to the provision of advice, however, relatively higher outdegree-centralization suggests that few local actors are particularly active in providing advice to other local farmers, in particular in the sugarcane network. The share of translocal connected egos and the share of egos acting as translocal brokers indicate that translocal advice is more equally accessible in the rice network than in the sugarcane network, but less effectively brokered among local actors.

\section{Actor network position and actor attributes}

This section classifies interviewed farmers according to their structural network position and presents the distribution of selected actor attributes. It thus reveals how and between whom advice is shared in translocal networks.

According to Fig. 7, the sugarcane network is characterized by a clear divide between less connected actors (75\%) and highly connected actors (25\%). The majority of actors play a rather passive role in advice sharing and receive more advice than they provide $(82 \%)$. While receivers of advice are mostly non-central actors $(68 \%)$, senders of advice are mostly central actors (11\%). These patterns suggest that advice sharing on sugarcane is unequally distributed and mostly driven by central actors. For the rice network, the difference between non-central actors (64\%) and central actors (36\%) is less pronounced. In comparison with the sugarcane network, receivers of advice are less frequent among non-central actors (52\%) but more frequent among central actors $(25 \%)$. At the same time, actors playing an active role in advice sharing are slightly more frequent among non-central actors (13\%) than among central actors (11\%). Altogether this suggests that advice in the rice network is more equally distributed and is less driven by central actors than in the sugarcane network.

As shown in Fig. 8a, in the sugarcane network, the share of translocal connected actors is significantly higher among central actors than among non-central actors, and so is the share of translocal brokers, receiving advice from translocal actors and providing the same kind of advice to local actors. This pattern suggests that well-connected actors are actively facilitating information flows between translocal and local actors. In comparison, in the rice network, the share of translocal connected actors and the share of translocal brokers is relatively lower among central actors. At the same time, the share of translocal connected actors among non-central actors is higher than in the sugarcane network. This pattern suggests that translocal advice regarding rice is more accessible among actors 
Fig. 7 Share of actors by actor network position in the sugarcane network and in the rice network

Sugarcane network

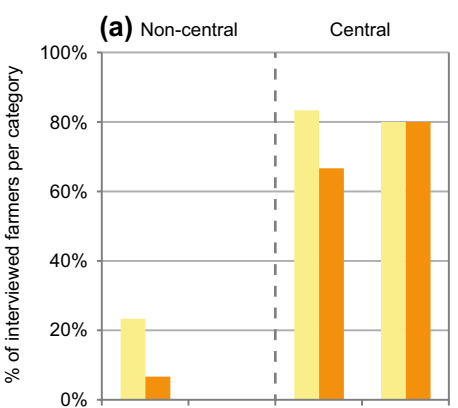

(b)

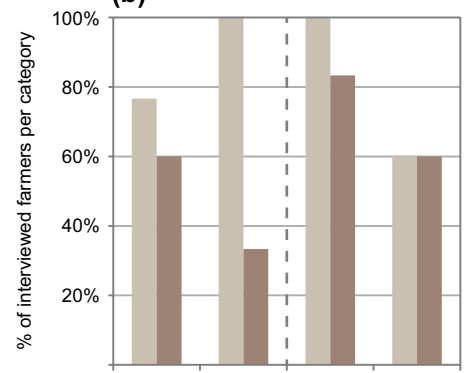

(c)

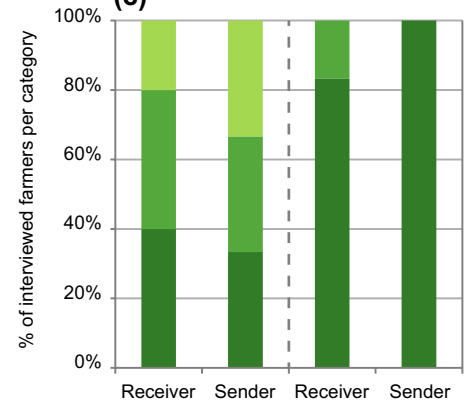

Sugarcane network

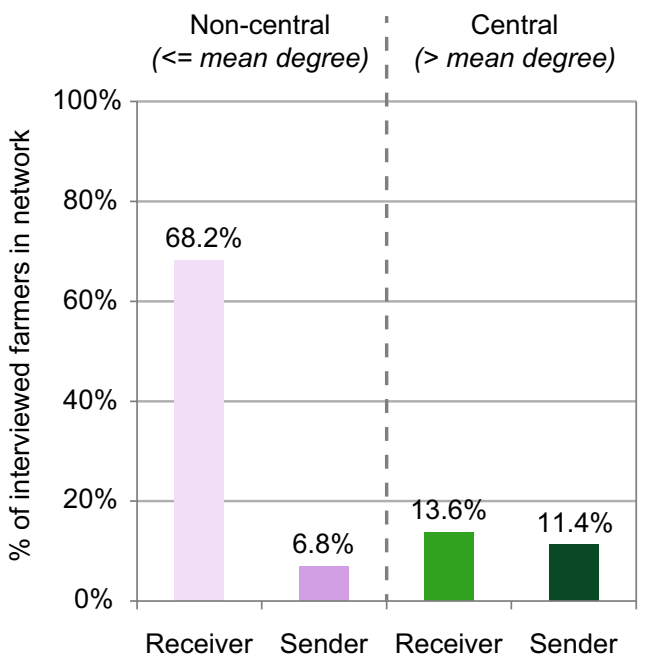

Rice network

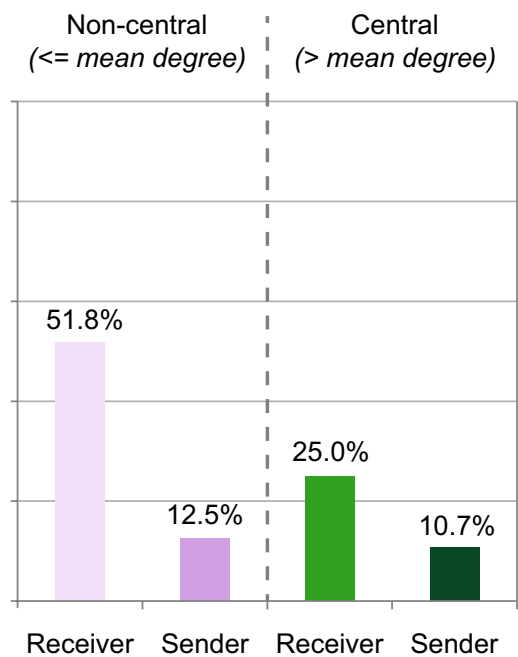

Rice network
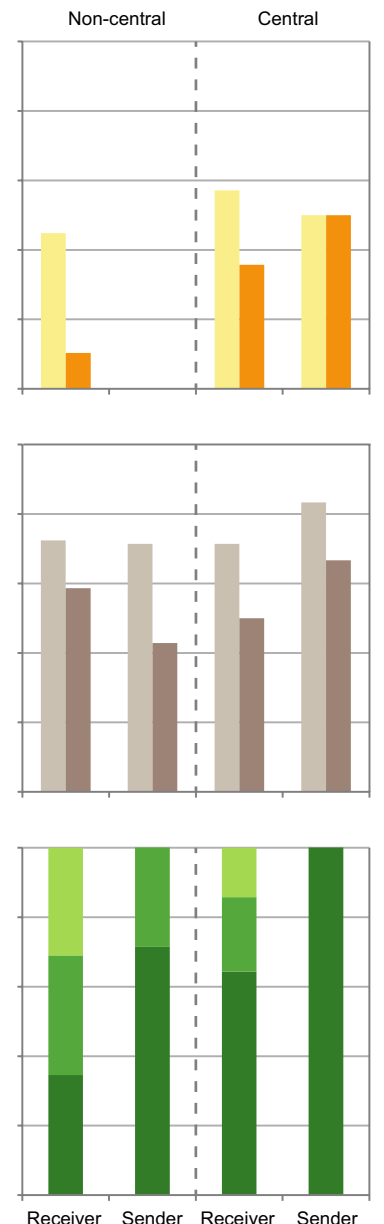

Sugarcane network

(d) Non-central

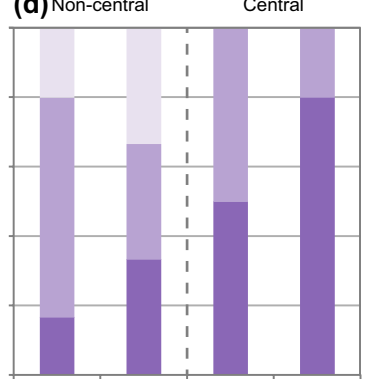

(e)

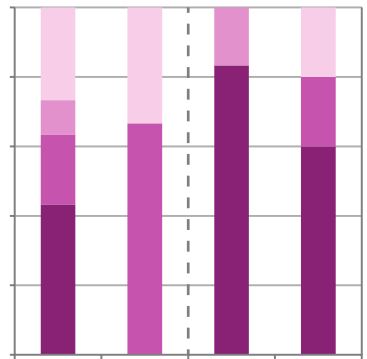

Receiver Sender Receiver Sender

a) Information flow

Translocally connected

- Translocal broker

b) Migration

At least one migrating household member - Postitive attitude towards migration

c) Main income source

Others

- Remittances

- Agriculture
Rice network
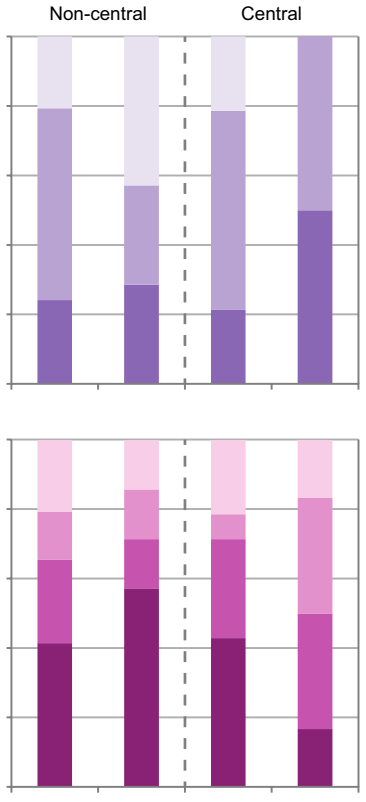

Receiver Sender Receiver Sender

d) Land cultivated

Smaller land

Medium land

- Larger land

e) Main information sources

Acquaintances

Kin

- Media

- Extension

Fig. 8 a-e Actor attributes by actor network position in the sugarcane network and in the rice network 
but less effectively brokered between translocal and local actors than advice regarding sugarcane.

Figure $8 \mathrm{~b}$ shows that, in the sugarcane network, involvement in migration is high across network positions but lowest among central senders. Although least involved in migration, the share of actors with positive attitude towards migration suggests that central senders are most satisfied with migration outcomes. Both central senders and central receivers tend to live off agriculture, while non-central actors depend to a greater extent on remittances as their first source of income (Fig. 8c). Also, central actors tend to farm larger amounts of land, while non-central actors tend to more frequently farm small and medium-sized plots (Fig. 8d). Central farmers, as well, tend to rely more on formal information provided by the agricultural extension and the media, while the share of farmers relying on informal sources of information such as kin and acquaintances is higher among non-central actors (Fig. 8e).

Unlike in the sugarcane network, involvement in migration is highest among central senders in the rice network. However, the share of actors with positive attitude towards migration suggests that non-central receivers are more satisfied with migration outcomes (Fig. 8b). Like in the sugarcane network, non-central receivers in the rice network depend most on remittances and other income sources, while central senders rely most on agriculture as main income source. However, unlike in the sugarcane network, also noncentral senders and central receivers show a high reliance on agricultural income (Fig. 8c). Also land size seems to be less related with centrality than in the sugarcane network. While the share of actors cultivating large amounts of land is highest among central senders, the share of actors cultivating small and medium-sized land is highest among central receivers and non-central receivers (Fig. 8d). The rice network is also more diverse in terms of information sources. Unlike in the sugarcane network, the share of actors relying on extension as the main source of information is lowest among central senders and highest among non-central senders, whereby the opposite is the case for the share of actors relying on kin and acquaintances (Fig. 8e). Altogether, these patterns suggest that actor' structural position in the rice network is less clearly related with actor characteristics than in the sugarcane network.

\section{Institutional context and key actors of agricultural change}

Making sense of the observed network patterns requires a broader understanding of the context in which agricultural change is materializing. This section summarizes qualitative data on institutional context and presents background information on selected key actors of recent changes in sugarcane and rice farming in the study site, derived from semi-structured interviews (sociograms of key actors see Online resource 3).

Changes in sugarcane farming have to be seen in the context of international market developments and national policies. In line with national development plans, processing facilities for sugarcane have recently been set up in the region. While public extension agencies such as the Bank of Agriculture and Agricultural Cooperatives (BAAC) and the district branch of the Department of Agricultural Extension (DOAE) focus on strengthening the production and marketing capacities of small-scale farmers, sugarcane factories provide trainings to contracted larger-scale farmers. Factory staff actively visits these farmers' plots to provide tailored knowledge, inputs and credit.

As the analysis of network positions and actor attributes reveals, local advice sharing on sugarcane is driven by a small group of experienced, larger-scale farmers, who are key actors for several reasons: First, as they successfully farm big sugarcane plantations, they are perceived as attractive sources of information. Second, as sugarcane farming requires high investments in land, seedlings and machines as well as detailed technical knowledge, they tend to have close ties to private and public extension agencies. Third, to fulfill their factory quotas, several large-scale farmers outsource production to small-scale farmers. In combination, these factors make larger-scale sugarcane farmers gatekeepers between informal local networks and formal extension. Indeed, the most influential farmer in the rice networks is not only larger-scale sugarcane farmer but also the local representative of the BAAC.

Also rice farming is driven by markets and policies, although to a lower extent than sugarcane farming. Extension-driven support includes advice on the certification and implementation of standards in rice farming by the BAAC or the promotion of sustainable farming practices through trainings offered by the district branch of the DOAE. However, the major change in rice farming - the shift from transplanting to rice broadcasting and cutting - has taken place without extension support.

The analysis of network positions and actor attributes in the rice network suggests that being a key-actor in the rice network is less clearly related with the size of land under cultivation and extension support but more with informal sources of information and migration. Indeed, a particularly influential actor is a small-scale farmer who gained inspiration for growing rice varieties during migration. As the initiator of a farmer group on sustainable rice production, she is well connected with extension agencies and an influential source of advice among local actors. Other key actors are early adopters of rice broadcasting and cutting who have gained inspiration during work or travel. As these key farmers did not receive any extension support in implementing broadcasting and cutting techniques, they are not necessarily 
among the most central and translocally connected actors in the rice network.

\section{Selected key actors in the sugarcane network}

PL is the official agricultural focal point in the village appointed by the BAAC. She has strong translocal ties to public extension agencies and coordinates villagers' participation in trainings and benefits from training herself. PL is a big sugarcane farmer and actively promotes the setting-up of a community collection point for small-scale sugarcane farmers. PL is also in charge of a project on "Good Agricultural Practices" and functions as a distributor of quality rice seeds. Accordingly, PL is among the most central and active translocal brokers in both the sugarcane and the rice network.

$\mathrm{BH}$ is a larger-scale sugarcane farmer from the neighboring province of Loei. As he sells seedlings to local farmers, he is frequently sought for advice on sugarcane. For his own farming activities $\mathrm{BH}$ derives inspiration from his family in Loei, making him a translocal broker and central sender in the sugarcane network. Although $\mathrm{BH}$ was among the first to cut rice, he plays a minor role in the rice network as he focuses on sugarcane farming and his rice plots are located in a less accessible area.

WC is the largest sugarcane farmer in the sub-district. She has close links with the sugarcane company and is actively contracting smaller-scale farmer in order to full-fill her quota. This makes WC the third most central actor in the sugarcane networks, in particular with regard to adoption advice.

\section{Selected key actors in the rice network}

WK is a return migrant who gained the inspiration to grow rice varieties during her work as a journalist in Bangkok. Today WK successfully heads a group of farmers growing rice varieties for specialty markets and actively advises group members on sustainable farming practices. In turn, she receives advice through the social network she established during her time in Bangkok. She is well connected to research centers, NGOs and public extension but also has strong ties to other central farmers, such as PL. Her networking skills make her the most central actor in the rice network and an agent of agricultural change.

BK is an old-aged small-scale farmer, who decided to adopt the rice broadcasting and cutting technique after observing farmers in central Thailand. Although he hardly exchanges advice with anyone else in the village, he is frequently referred to as a "good example," as his plot is directly located at the road to the market and villagers can easily observe the success of his practices. This makes him a central sender in the rice network, ranking sixth in terms of centrality but first in terms of the ratio between in- and out-degree.

ST is a seasonal migrant worker and small-scale rice farmer, driving sugarcane trucks in the dry season. During a trip to another province he observed the practice of rice broadcasting. With money from migration he bought a machine seeder and successfully started a small business, offering broadcasting services to other villagers. This makes him a central and active actor in the rice network, mostly regarding implementation advice.

\section{Discussion}

In order to judge the relevance of translocal networks for agricultural innovation in the study site, we interpret the distribution and composition of advice and characterize the different innovation systems, in which advice sharing on sugarcane and rice farming operates. Finally, we zoom in on the role of migration-related knowledge transfers for particular changes in rice farming, and shed attention to the importance of migration-related knowledge.

\section{Local versus translocal: distribution and composition of advice}

By analyzing the distribution and composition of advice regarding changes in sugarcane and rice farming over a period of five years, we can show that in mobile and highly connected rural areas, such as the study site of Ban Chai, agriculture-related social interactions are far from self-contained (Matous 2015). Depending on the crop under study, a quarter to a third of all advice that has facilitated changes was provided through translocal ties, influencing one-third to two-fifth of all interviewed farmers. This relatively high level of translocal connectedness in agricultural advice sharing indicates that the "de-localization of rural livelihoods" (Rigg 2006; Rigg et al. 2012) also matters for agricultural innovation.

When looking at the composition of translocal advice in more detail, results reveal that extension-related translocal advice dominated over informal migration-related translocal advice in both the sugarcane and rice network. Thus, even in a context in which most of the households are involved in migration, migration does not necessarily result in migration-related translocal advice. At the same time, formal translocal ties were mostly weak, while informal translocal ties were to an equal share composed of strong and weak ties, suggesting qualitative differences between migrationrelated advice and extension-related advice.

Besides a relatively high level of translocal connectedness, results underline the prevailing local character of agricultural advice sharing in Northeast Thailand. In the study 
site of Ban Chai, over the last five years, the majority of advice regarding changes in sugarcane and rice farming was provided through local ties and, in particular, through strong local ties. This finding is in line with other studies on agricultural innovation in small-scale farming which point to the critical role of close-knit networks in facilitating knowledge exchange on seeds, crops and practices (Van den Broeck and Dercon 2011; Tatlonghari et al. 2012; Ricciardi 2015; Mekonnen et al. 2018).

Further, results indicate spatial differences in the provision of adoption and implementation advice. While decisions to adopt a new crop or practice were to a high extent facilitated by strong local ties, implementation advice was facilitated by a relatively higher share of translocal ties, and in particular, weak translocal ties. The local bias in adoption advice we interpret as an indication that incentives to adopt a new crop or practice-in particular in the beginning of the diffusion process-are more compelling, if already implemented by a local and trusted peer (Conley and Udry 2001; Bandiera and Rasul 2006).

The relatively higher share of translocal ties in implementation advice - in particular with regard to rice farmingsuggests that problem-oriented advice is not necessarily more compelling if provided by socially and geographically close actors. Whilst, in general, strong ties are particularly effective in translating knowledge into practice (Darr and Pretzsch 2008), seeking solutions from distant sources might be considered particularly relevant in a region like Northeast Thailand, with its rapidly transforming agricultural systems and high exposure to correlated risks, such as droughts and drought-related diseases (Naruchaikusol 2016; Rambo 2017).

More particularly, the finding that translocal implementation advice is predominantly sought through weak formal ties points to role of agricultural extension services in providing technical, problem-oriented assistance. In contrast, the relatively higher share of informal ties in translocal adoption advice suggests a certain role of migration-related translocal ties in facilitating adoption decisions.

\section{Top-down versus bottom-up: innovation systems}

Although instructive in characterizing the socio-spatial patterns of translocal advice sharing, the sole consideration of quantitative tie distribution is not sufficient for judging the relevance of translocal networks. Contextualizing quantitative network patterns with qualitative information on institutional context and key actors, we have revealed that advice sharing on sugarcane and rice operates through different agricultural innovation systems.

The sugarcane network, we interpret as the structural manifestation of a sparse but highly effective top-downoriented extension system (Isaac 2012; Bourne et al. 2017) operating in the context of national policies and market dynamics. In this system, translocal advice is mostly provided by a few private and public extension agencies at the district level, while recipients of translocal advice are mostly centrally positioned actors. Central actors tend to be larger-scale farmers, which are less involved in migration and depend less on remittances but do rely on agricultural activities as their main source of income, unlike non-central actors. These "elite farmers" actively broker advice between translocal and local actors, hence linking between formal and informal knowledge systems (Isaac 2012). Larger-scale farmers, such as BH or WK, act as role models in sparse and non-redundant local networks, as observable indicators of economic success, such as plot size and machinery, make them attractive sources of advice for small-scale farmers. Moreover, larger-scale farmers-which are under contract with sugarcane companies-actively source-out production to small-scale farmers, not only providing advice but also inputs and services. Given this effective arrangement, topdown translocal innovation flows, driven by extension and brokered by elite farmers, profoundly impact local sugarcane farming.

In contrast, changes in rice farming are less dominated by extension and elite farmers but to a higher extent by migration-related knowledge transfers. In the rice network, translocal ties are more frequent and also more equally distributed among farmers than in the sugarcane network. Also actor centrality is less clearly related to land cultivation but more with involvement in migration. These findings indicate that advice seeking through translocal networks is a viable adaptation strategy (Scheffran et al. 2012), especially for the less connected and economically less successful farmers (Hoang et al. 2006). Migration-related translocal innovation flows are particularly evident for the shift from transplanting to rice broadcasting and cutting, which was first implemented by a small number of return migrants. As these changes materialized without extension support, they can be interpreted as successful bottom-up innovations. However, at the same time, the lower share of translocal brokers among central actors and the lower density of the rice network suggest that translocal advice is less effectively shared between translocal and local actors than in the sugarcane network. Hence, a closer look at particular changes in rice farming is needed in order to judge the relevance of translocal networks for agricultural innovation.

\section{Translocal networks versus embodied experience: migration-related translocal knowledge transfers}

In the following, we place attention on two different forms of migration-related knowledge transfers: direct transfers through translocal networks and indirect transfers through embodied migration experience. 
The example of sustainable rice diversification illustrates how agricultural innovations can spread successfully, if translocal and local networks are combined. The rice business of WK, a young return migrant, is thriving, because she can draw on her migration-related translocal network for accessing technical and financial advice, inspiration and new ideas that would be not available locally. At the same time, she can rely on her local network for disseminating external knowledge and for coordinating the production process. In particular, her kinship ties, as the daughter of an influential family, and her friendship with PL, helped her to gain acceptance from local farmers and to build up a sufficiently big group of producers. Hence, the example of WK demonstrates the critical role of motivated and dedicated "boundary spanning individuals" (Klerkx et al. 2010) and shows that the right mix of strong and weak ties (Newman and Dale 2005; Bodin et al. 2006) and-more specifically-a combination of long distance ties with dense local networks, can be highly effective in fostering agricultural innovations (Isaac and Matous 2017; Matous and Todo 2018).

In contrast, the example of broadcasting and cutting illustrates that translocal knowledge transfers do not necessarily require boundary spanning individuals. Translocal knowledge transfers also can be initiated by return migrants applying agricultural experiences and knowledge gained in other places (Isaac et al. 2014; Salpeteur et al. 2016). Early adopters of broadcasting and cutting, such as BK or ST, gained inspiration for changing rice farming practices from observing farmers in other regions of Thailand during migration but did not seek translocal adoption or implementation advice from them. Instead, after return, they implemented the observed agricultural practice in a trial-and-error fashion. At the local level, these early adopters are of relevance not due to their role as translocal brokers but due to their role as "good examples". As the technology of broadcasting and cutting is easily observable and replicable, it spreads easily among local farmers, even in the absence of direct advice seeking. A further driver of fast diffusion is the provision of commercial broadcasting and cutting services by particular early adopters.

\section{Intensification versus extensification: Viability of migration-related knowledge}

Understanding why particular changes are more likely to be facilitated through migration-related knowledge transfers also requires considering the kind of knowledge migrants acquire during migration and its applicability to rural livelihoods. As the majority of migrants from Northeast Thailand work in in the construction sector or in factories in the metropolitan areas of Thailand or abroad (Peth et al. 2018; Porst and Sakdapolrak 2018), they are unlikely to gain knowledge about different agro-ecological environments during migration (Isaac et al. 2014; Matous and Todo 2018). Even in the case of migrants working in modern agriculture, e.g. in Southern Thailand or abroad, experiences rarely result in agricultural changes after return because migrants gain only fragmented knowledge and because migration usually does not yield sufficient investment capital. In particular, sugarcane farming is highly capital and resource intensive (e.g. land, labor, inputs) and requires economies of scale. Hence, it is more attractive to larger-scale farmers focusing on intensive agriculture as main income source. Instead, the observed changes in rice farming, such as rice broadcasting and cutting, do not require specific technical knowledge, expensive machinery or specific market channels. Moreover, broadcasting and cutting can be gradually implemented alongside traditional practices of transplanting and hence offers opportunities for extensification in accordance to declining labor resources of multi-sited households and in accordance to increasingly volatile rainfall patterns. The spread of this agricultural innovation, we thus interpret as an example of how translocal knowledge transfers can foster adaptive capacity in the context of migration and climate change (Scheffran et al. 2012; Sakdapolrak et al. 2016).

\section{Conclusions}

By means of formal SNA, a questionnaire survey, and semistructured interviews, this case study provides nuanced insights into the role of translocal and translocal knowledge transfers for adaptive changes in small-scale farming advice sharing networks communities in Northeast Thailand. We have mapped the distribution and composition of advice regarding changes in sugarcane and rice farming over a period of five years, investigated structural patterns of advice sharing networks, and identified the institutional context and key actors of agricultural change. With this, we are able to answer our research questions and to substantiate the discussion on the role of translocal networks in agricultural innovation (Scheffran et al. 2012; Sakdapolrak et al. 2016; Matous and Todo 2018).

First, in the context of migration and de-localization of rural livelihoods (Rigg 2006; Rigg et al. 2012), advice relevant for agricultural changes originates to an increasing extent from translocal sources. In overall quantitative terms, agricultural advice sharing remains a local phenomenon, facilitated dominantly by sparse but close-knit networks between local farmers. Local advice sharing is particularly relevant in the case of adoption decisions, as incentives to adapt a new crop or practice are more compelling, if provided by successful local peers (Conley and Udry 2001; Bandiera and Rasul 2006).

Second, even in predominantly local advice sharing networks, a few translocal ties can facilitate translocal 
innovation transfers (Matous and Todo 2018). The relevance of translocal ties, however, depends on the agricultural change under study and the structural features of the related innovation systems. In an efficiently structured network, with few translocal ties but centralized brokerage between formal extension and non-redundant informal farmer networks, such as the sugarcane network, topdown innovation flows driven by market developments and polices are likely to have a bigger impact than in a more translocal-oriented but less efficiently structured network, such as the rice network.

Third, particular-key actors can make difference. As the example of sustainable rice diversification demonstrates, single boundary spanning individuals (Klerkx et al. 2010) motivated to make a change to their agricultural livelihoods can facilitate bottom-up innovations by linking translocal and local formal and informal networks. As the example of rice broadcasting and cutting demonstrates, bottom-up innovation can materialize, even in the absence of extension support or boundary spanning individuals, if return migrants pass on their embodied migration experience onto local peers, either actively through advice sharing or passively through observation.

Fourth, context matters. Particular changes, such as the spread of sugarcane farming, are only viable in the context of adequate market infrastructure, policies, and extension systems. The potential of migration-related translocal knowledge transfers is particularly evident with regard to adaptive changes that are geared towards limited household resources and that are compatible with social practices of farming. However, the viability of migration-related knowledge transfers depends on the type and destination of migration and is higher if migrants are exposed to different agro-ecological contexts (Matous and Todo 2018). Under these conditions, migration-related knowledge transfers can potentially enable farmers to innovate, who may typically be overlooked by formal extension systems due to their lack of resources and institutional ties (Hoang et al. 2006).

We conclude that research and extension services interested in leveraging agricultural innovations for adaptive change in a more inclusive way should consider institutionalized knowledge and migration-related knowledge transfers as complementary sources of agricultural innovation. In order to disentangle the socio-spatial patterns underlying agricultural innovation, we argue that a translocal network perspective is instructive, if combining quantitative and qualitative approaches.

Acknowledgements This article is based on research funded by the German Federal Ministry of Education and Research, Grant Number 01LN1309A. The responsibility for the contents of this publication lies with the authors. We thank the numerous interviewees for providing insights in their agricultural activities and their sources of advice. In particular we thank our excellent research assistants, Pichapon Robru and Nootchanok Jitpakdee, for facilitating and translating interviews, and Raks Thai Foundation for organizational support.

Open Access This article is distributed under the terms of the Creative Commons Attribution 4.0 International License (http://creativeco mmons.org/licenses/by/4.0/), which permits use, duplication, adaptation, distribution and reproduction in any medium or format, as long as you give appropriate credit to the original author(s) and the source, provide a link to the Creative Commons license and indicate if changes were made.

\section{References}

Arora, S. 2012. Farmers' participation in knowledge circulation and the promotion of agroecological methods in South India. Journal of Sustainable Agriculture 36 (2): 207-235. https://doi. org/10.1080/10440046.2011.620231.

Bandiera, O., and I. Rasul. 2006. Social networks and technology adoption in Northern Mozambique. The Economic Journal 116 (514): 869-902. https://doi.org/10.1111/j.1468-0297.2006.01115.x.

Berdegué, J.A., T. Rosada, and A.J. Bebbington. 2014. The rural transformation. In International development: Ideas, experience, and prospects, ed. B. Currie-Alder, R. Kanbur, D.M. Malone, and R. Medhora, 463-478. Oxford: Oxford University Press. https://doi. org/10.1093/acprof:oso/9780199671656.001.0001.

Binz, C., B. Truffer, and L. Coenen. 2014. Why space matters in technological innovation systems-Mapping global knowledge dynamics of membrane bioreactor technology. Research Policy 43 (1): 138-155. https://doi.org/10.1016/j.respol.2013.07.002.

Bodin, Ö., B. Crona, and H. Ernstson. 2006. Social networks in natural resource management: What is there to learn from a structural perspective? Ecology and Society 11 (2): r2.

Bodin, Ö., and B. Crona. 2009. The role of social networks in natural resource governance: What relational patterns make a difference? Global Environmental Change 19 (3): 366-374. https://doi. org/10.1016/j.gloenvcha.2009.05.002.

Bolíbar, M. 2015. Macro, meso, micro: Broadening the 'social' of social network analysis with a mixed methods approach. Quality \& Quantity 50 (5): 2217-2236. https://doi.org/10.1007/s1113 5-015-0259-0.

Bourne, M., A. Gassner, P. Makui, A. Muller, and J. Muriuki. 2017. A network perspective filling a gap in assessment of agricultural advisory system performance. Journal of Rural Studies 50: 30-44. https://doi.org/10.1016/j.jrurstud.2016.12.008.

Brickell, K., and A. Datta. 2011. Translocal geographies. Spaces, places, connections. London, UK: Routledge.

Calvet-Mir, L., M. Calvet-Mir, J.L. Molina, and V. Reyes-García. 2012. Seed exchange as an agrobiodiversity conservation mechanism. A case study in Vall Fosca, Catalan Pyrenees, Iberian Peninsula. Ecology and Society 17 (1): 29. https://doi.org/10.5751/ES-04682 -170129 .

Choenkwan, S., and M. Fisher. 2018. Introduction to the special section: Agrarian transformation in Thailand-Commodities, landscapes, and livelihoods. Forest and Society 2 (2): 112-120. https ://doi.org/10.24259/fs.v2i2.5356.

Conley, T., and C. Udry. 2001. Social learning through networks: The adoption of new agricultural technologies in Ghana. American Journal of Agricultural Economics 83 (3): 668-673. https://doi. org/10.1111/0002-9092.00188.

Darr, D., and J. Pretzsch. 2008. Mechanisms of innovation diffusion under information abundance and information scarcityOn the contribution of social networks in group vs. individual extension approaches in semi-arid Kenya. The Journal of 
Agricultural Education and Extension 14 (3): 231-248. https:// doi.org/10.1080/13892240802207676.

Das, R.J. 2001. The spatiality of social relations: An Indian case-study. Journal of Rural Studies 17 (3): 347-362. https://doi.org/10.1016/ S0743-0167(00)00034-6.

Ellis, F. 2003. A livelihoods approach to migration and poverty reduction. Paper commissioned by the Department for International Development (DFID). CiteSeerX. https://citeseerx.ist.psu.edu/ viewdoc/download?doi=10.1.1.553.5678\&rep=rep1\&type $=$ pdf. Accessed 13 Mar 2019.

Granovetter, M.S. 1973. The strength of weak ties. American Journal of Sociology 78 (6): 1360-1380.

Greiner, C., and P. Sakdapolrak. 2013. Translocality: Concepts, applications and emerging research perspectives. Geography Compass 7 (5): 373-384. https://doi.org/10.1111/gec3.12048.

Hennig, M., U. Brandes, J. Pfeffer, and I. Mergel. 2012. Studying social networks: A guide to empirical research. Frankfurt: Campus Verlag.

Hoang, L.A., J.-C. Castella, and P. Novosad. 2006. Social networks and information access: Implications for agricultural extension in a rice farming community in northern Vietnam. Agriculture and Human Values 23 (4): 513-527. https://doi.org/10.1007/s1046 0-006-9013-5.

Hollstein, B., and F. Straus. 2006. Qualitative Netzwerkanalyse. Konzepte, Methoden, Anwendungen. Wiesbaden: Springer.

Isaac, M.E. 2012. Agricultural information exchange and organizational ties: The effect of network topology on managing agrodiversity. Agricultural Systems 109: 9-15. https://doi.org/10.1016/j. agsy.2012.01.011.

Isaac, M.E., L.C.N. Anglaaere, D.S. Akoto, and E. Dawoe. 2014. Migrant farmers as information brokers: Agroecosystem management in the transition zone of Ghana. Ecology and Society 19 (2): 56. https://doi.org/10.5751/ES-06589-190256.

Isaac, M.E., and P. Matous. 2017. Social network ties predict land use diversity and land use change: A case study in Ghana. Regional Environmental Change 17 (6): 1823-1833. https://doi. org/10.1007/s10113-017-1151-3.

Jessop, B., N. Brenner, and M. Jones. 2008. Theorizing sociospatial relations. Environment and Planning D 26: 389-401. https://doi. org/10.1068/d9107.

Klerkx, L., N. Aarts, and C. Leeuwis. 2010. Adaptive management in agricultural innovation systems: The interactions between innovation networks and their environment. Agricultural Systems 103 (6): 390-400. https://doi.org/10.1016/j.agsy.2010.03.012.

Kossinets, G. 2006. Effects of missing data in social networks. Social Networks 28 (3): 247-268. https://doi.org/10.1016/j.socne t.2005.07.002.

Marsden, P.V. 2005. Recent developments in network measurement. In Models and methods in social network analysis, ed. P.J. Carrington, J. Scott, and S. Wasserman, 8-30. New York, NY: Cambridge University Press.

Matous, P., Y. Todo, and D. Mojo. 2013. Roles of extension and ethno-religious networks in acceptance of resource-conserving agriculture among Ethiopian farmers. International Journal of Agricultural Sustainability 11 (4): 301-316. https://doi. org/10.1080/14735903.2012.751701.

Matous, P. 2015. Social networks and environmental management at multiple levels: Soil conservation in Sumatra. Ecology and Society 20 (3): 37. https://doi.org/10.5751/ES-07816-200337.

Matous, P., and Y. Todo. 2018. An experiment in strengthening the networks of remote communities in the face of environmental change: Leveraging spatially distributed environmental memory. Regional Environmental Change 18 (6): 1741-1752. https://doi. org/10.1007/s10113-018-1307-9.

Mekonnen, D.A., N. Gerber, and J.A. Matz. 2018. Gendered social networks, agricultural innovations, and farm productivity in Ethiopia.
World Development 105: 321-355. https://doi.org/10.1016/j.world dev.2017.04.020.

Mikhail, M., A. Fencl, S. Naruchaikusol, and E. Kemp-Benedict. 2010. Innovation and diffusion of sustainable agricultural water resource management in a changing climate: A case study in Northeast Thailand. Stockholm Environment Institute, Project report-2010. CAKE. https://www.cakex.org/sites/default/files/documents/sei2010-innovation-diffusion-agriculture-thailand.pdf. Accessed 13 Mar 2019.

Naruchaikusol, S. 2016. Climate change in Thailand. TransRe Factsheet, Issue 2. transre. http://transre.org/files/9014/6859/1818/ Climate_Change_in_Thailand_TransRe_Fact_Sheet_No._2.pdf. Accessed 13 Mar 2019.

Newman, L., and A. Dale. 2005. Network structure, diversity, and proactive resilience building: A response to Tompkins and Adger. Ecology and Society 10 (1): r2.

Peth, S.A., H. Sterly, and P. Sakdapolrak. 2018. Between the village and the global city: The production and decay of translocal spaces of Thai migrant workers in Singapore. Mobilities 13 (4): 455-472. https://doi.org/10.1080/17450101.2018.1449785.

Porst, L., and P. Sakdapolrak. 2018. Advancing adaptation or producing precarity? The role of rural-urban migration and translocal embeddedness in navigating household resilience in Thailand. Geoforum 97: 35-45. https://doi.org/10.1016/j.geoforum.2018.10.011.

Promburom, P., and P. Sakdapolrak. 2012. Where the rain falls project. Case study: Thailand. Results from Thung Hua Chang District, Northern Thailand. UNU EHS. https://collections.unu.edu/eserv /UNU:1845/pdf10818.pdf. Accessed 13 Mar 2019.

Rambo, A.T. 2017. The agrarian transformation in Northeast Thailand: A review of recent research. Southeast Asian Studies 6 (2): 211-245. https://doi.org/10.20495/seas.6.2_211.

Ricciardi, V. 2015. Social seed networks: Identifying central farmers for equitable seed access. Agricultural Systems 139: 110-121. https://doi.org/10.1016/j.agsy.2015.07.002.

Rigg, J. 2006. Land, farming, livelihoods, and poverty: Rethinking the links in the Rural South. World Development 34 (1): 180-202. https://doi.org/10.1016/j.worlddev.2005.07.015.

Rigg, J., and A. Salamanca. 2011. Connecting lives, living, and location. Mobility and spatial signatures in Northeast Thailand, 1982-2009. Critical Asian Studies 43 (4): 551-575. https://doi. org/10.1080/14672715.2011.623522.

Rigg, J., A. Salamanca, and M. Parnwell. 2012. Joining the dots of agrarian change in Asia: A 25 year view from Thailand. World Development 40 (7): 1469-1481. https://doi.org/10.1016/j.world dev.2012.03.001.

Rigg, J., and K. Oven. 2015. Building liberal resilience? A critical review from developing rural Asia. Global Environmental Change 32: 175-186. https://doi.org/10.1016/j.gloenvcha.2015.03.007.

Rockenbauch, T., and P. Sakdapolrak. 2017. Social networks and the resilience of rural communities in the Global South: A critical review and conceptual reflections. Ecology and Society 22 (1): 10. https://doi.org/10.5751/ES-09009-220110.

Rodima-Taylor, D., M.F. Olwig, and N. Chhetri. 2012. Adaptation as innovation, innovation as adaptation: An institutional approach to climate change. Applied Geography 33: 107-111. https://doi. org/10.1016/j.apgeog.2011.10.011.

Sakdapolrak, P., S. Naruchaikusol, K. Ober, S.A. Peth, L. Porst, T. Rockenbauch, and V. Tolo. 2016. Migration in a changing climate. Towards a translocal social resilience approach. Die Erde 147 (2): 81-94. https://doi.org/10.12854/erde-147-6.

Salpeteur, M., H.H.R. Patel, J.L. Molina, A.L. Balbo, X. RubioCampillo, V. Reyes-García, and M. Madella. 2016. Comigrants and friends: Informal networks and the transmission of traditional ecological knowledge among seminomadic pastoralists of Gujarat, India. Ecology and Society 21 (2): 20. https://doi.org/10.5751/ ES-08332-210220. 
Salpeteur, M., L. Calvet-Mir, I. Diaz-Reviriego, and V. Reyes-García. 2017. Networking the environment: Social network analysis in environmental management and local ecological knowledge studies. Ecology and Society 22 (1): 41. https://doi.org/10.5751/ ES-08790-220141.

Scheffran, J., E. Marmer, and P. Sow. 2012. Migration as a contribution to resilience and innovation in climate adaptation: Social networks and co-development in northwest Africa. Applied Geography 33: 119-127. https://doi.org/10.1016/j.apgeog.2011.10.002.

Schut, M., L. Klerkx, J. Rodenburg, J. Kayeke, L.C. Hinnou, C.M. Raboanarielina, P.Y. Adegbola, A. van Ast, and L. Bastiaans. 2015. RAAIS: Rapid appraisal of agricultural innovation systems (Part I). A diagnostic tool for integrated analysis of complex problems and innovation capacity. Agricultural Systems 132: 1-11. https://doi.org/10.1016/j.agsy.2014.08.009.

Scott, J. 2013. Social network analysis, 3rd ed. London: Sage Publications.

Spielman, D.J., K. Davis, M. Negash, and G. Ayele. 2011. Rural innovation systems and networks: Findings from a study of Ethiopian smallholders. Agriculture and Human Values 28 (2): 195-212. https://doi.org/10.1007/s10460-010-9273-y.

Steinbrink, M. 2009. Leben zwischen Land und Stadt. Migration, Translokalität und Verwundbarkeit in Südafrika. Wiesbaden: Springer.

Tatlonghari, G., T. Paris, V. Pede, I. Siliphouthone, and R. Suhaeti. 2012. Seed and information exchange through social networks: The case of rice farmers of Indonesia and Lao PDR. Sociology Mind 2 (2): 169-176. https://doi.org/10.4236/sm.2012.22022.

Thuo, M., A.A. Bell, B.E. Bravo-Ureta, M.A. Lachaud, D.K. Okello, E. Nasambu Okoko, N.L. Kidula, C.M. Deom, and N. Puppala. 2014. Effects of social network factors on information acquisition and adoption of improved groundnut varieties: The case of Uganda and Kenya. Agriculture and Human Values 31 (3): 339-353. https ://doi.org/10.1007/s10460-014-9486-6.

Van den Broeck, K., and S. Dercon. 2011. Information flows and social externalities in a Tanzanian banana growing village. Journal of Development Studies 47 (2): 231-252. https://doi. org/10.1080/00220381003599360.

Violon, C., M. Thomas, and E. Garine. 2016. Good year, bad year: changing strategies, changing networks? A two-year study on seed acquisition in Northern Cameroon. Ecology and Society 21 (2): 34. https://doi.org/10.5751/ES-08376-210234.

Wasserman, S., and K. Faust. 1994. Social network analysis. Methods and applications. Cambridge, UK: Cambridge University Press.

Wossen, T., T. Berger, T. Mequaninte, and B. Alamirew. 2013. Social network effects on the adoption of sustainable natural resource management practices in Ethiopia. International Journal of Sustainable Development \& World Ecology 20 (6): 477-483. https:// doi.org/10.1080/13504509.2013.856048.

Publisher's Note Springer Nature remains neutral with regard to jurisdictional claims in published maps and institutional affiliations.

Till Rockenbauch is a Research Associate and PhD Candidate at the University of Bonn. He is a geographer by training with a background in Development and Social-Ecological Systems Research. Currently, he works towards a translocal network perspective on rural resilience to environmental risks. In order to understand how migration and translocal networks relate to the capacity of rural households to cope and to adapt, he is triangulating formal social network analysis with qualitative and participatory approaches.

Patrick Sakdapolrak is Professor for Population Geography and Demography at the University of Vienna. He specializes in population dynamics, environmental change and development processes, with a focus on the topics of migration and displacement as well as health and disease. He studied Geography and Development Research in Heidelberg and Wollongong, Australia, and received his $\mathrm{PhD}$ at the University of Bonn.

Harald Sterly is a Research Associate in the Working Group for Population Geography and Demography at the University of Vienna. His research focus lies on the spatial and social aspects of migration, urbanization, and technological change. He studied Geography and Development at the Universities of Cologne and Berlin, and is pursuing his $\mathrm{PhD}$ at the University of Cologne. 